Article

\title{
Novel Protocol for Acute In Situ Ecotoxicity Test Using Native Crustaceans Applied to Groundwater Ecosystems
}

\author{
Andrea Castaño-Sánchez ${ }^{1}$, Florian Malard ${ }^{2}$, Gabriela Kalčíková ${ }^{3}$ (D) and Ana Sofia P. S. Reboleira ${ }^{1,4, *(\mathbb{D})}$ \\ 1 Natural History Museum of Denmark, University of Copenhagen, 2100 Copenhagen, Denmark; \\ andrea.sanchez@snm.ku.dk \\ 2 Univ Lyon, Université Claude Bernard Lyon 1, CNRS, ENTPE, UMR 5023 LEHNA, \\ F-69622 Villeurbanne, France; florian.malard@univ-lyon1.fr \\ 3 Faculty of Chemistry and Chemical Technology, University of Ljubljana, SI-1000 Ljubljana, Slovenia; \\ gabriela.kalcikova@fkkt.uni-lj.si \\ 4 Centre for Ecology, Evolution and Environmental Changes (cE3c) and Departamento de Biologia Animal, \\ Faculdade de Ciências, Universidade de Lisboa, 1749-016 Lisbon, Portugal \\ * Correspondence: asreboleira@fc.ul.pt
}

Citation: Castaño-Sánchez, A. Malard, F.; Kalčíková, G.; Reboleira, A.S.P.S. Novel Protocol for Acute In Situ Ecotoxicity Test Using Native Crustaceans Applied to Groundwater Ecosystems. Water 2021, 13, 1132. https://doi.org/10.3390/w13081132

Academic Editor: Lorenzo Proia

Received: 22 March 2021

Accepted: 16 April 2021

Published: 20 April 2021

Publisher's Note: MDPI stays neutral with regard to jurisdictional claims in published maps and institutional affiliations.

Copyright: (c) 2021 by the authors. Licensee MDPI, Basel, Switzerland. This article is an open access article distributed under the terms and conditions of the Creative Commons Attribution (CC BY) license (https:// creativecommons.org/licenses/by/ $4.0 /)$.

\begin{abstract}
Current standardized laboratory test protocols use model species that have limitations to accurately assess native species responses to stressors. We developed and tested a novel acute in situ protocol for testing field-collected organisms. We used Asellus aquaticus and $\mathrm{NaCl}$ as a reference toxicant to test for the effects of location (laboratory vs. in situ), medium (synthetic vs. field water), substrate (presence vs. absence), and protocol replicability. We further tested the protocol using groundwater-adapted isopods: Proasellus assaforensis for the effect of location, P. cavaticus of medium and P. lusitanicus of substrate. Our results showed that A. aquaticus' lethality obtained with the novel acute in situ protocol did not significantly differ from those from laboratory testing. However, laboratory tested $P$. assaforensis showed a higher sensitivity, suggesting that its acclimation to laboratory conditions might have pernicious effects. A. aquaticus and P. cavaticus showed a higher mortality using synthetic medium in situ and under laboratory conditions, which overestimated the stressor's effect. Besides, substrate use had no significant effect. The novel acute in situ protocol allows the use of native species under realistic scenarios. It is particularly well adapted for assessing the risk of groundwater ecosystems but it can be applied to a wide range of ecosystems.
\end{abstract}

Keywords: groundwater ecology; groundwater ecotoxicology; stygofauna; in situ exposure; sitespecific assessment

\section{Introduction}

Ecotoxicological approaches are indispensable tools in environmental risk assessment (ERA). The inference of ecological impacts is challenged by the complex interactions within ecosystems [1]. The sensitivity to anthropogenic stressors varies markedly among species, and environmental variability, together with food web structure, plays an important role in determining the organisms' response [2,3].

Acute tests are well replicated and cost-effective tools, which are a reliable and essential support for ERA and decision making [4]. The use of acute tests has yielded a massive amount of ecotoxicological data, compiled and available in international databases (e.g., [5]). Despite the incremental complexity of ecotoxicological studies and the encouragement of ERA guidelines to use long-term studies [6], acute toxicity tests have remained an important source of data for species distributions models [5,7-10].

Nevertheless, ecotoxicological results provided in the databases usually correspond to the sensitivity of a reduced number of model species or of species reared under standard laboratory (lab) conditions, neglecting the use of native species [11]. Moreover, the complex exposure dynamics of chemical mixtures observed in natural freshwater matrices leads 
to the application of site-specific assessment protocols, which experimentally prioritizes ecological realism [12].

In order to increase ecological realism, the use of relevant species for specific ecosystems is becoming widespread in ecotoxicity tests that focus on site-specific assessment [12-15]. Native organisms are presumably adapted to local environmental conditions and their use for in situ tests (e.g., in situ methodology using caged organisms) also prevents the introduction of exotic or invasive species [13]. However, the use of native species for ecotoxicology has some limitations since native organisms have often an unknown life history and some traits are difficult to assess prior to exposure to stressors, e.g., the organisms age [13].

Several studies are compelled to use field collected organisms in lab testing procedures because many species fail to adapt to lab holding conditions, and due to the lack of culturing methods for non-target species [16,17]. The use of field collected organisms under lab conditions potentially adds an extra stress associated to the manipulation, transportation and lab acclimation [13]. It may decrease the organisms' fitness, thereby overestimating the organisms' sensitivity to stressors [18]. Moreover, natural populations often show a limited number of specimens. Therefore, the use of field collected organisms often implies an increment in experimental costs compared to testing lab cultured organisms, due to repeated sampling [12,16].

Establishing lab cultures of organisms for ecotoxicological testing is particularly challenging for a number of ecosystems including subterranean, anchialine, and deep-sea ecosystems [16,17]. Environmental conditions in these difficult-to-access ecosystems cannot be reproduced in the lab and the ecological requirements of many species are not known. Still, a realistic ecotoxicological assessment of anthropogenic stressors is essential to define thresholds for establishing conservation measures in these ecosystems [16,19].

Generating ecotoxicological data for groundwater-adapted organisms is especially challenging [16]. Access to groundwater ecosystems is remotely small compared to their spatial extent, which makes their biodiversity largely unknown to science [20]. Furthermore, groundwater-adapted fauna is unique, composed of highly specialized organisms with characteristic morpho-physiological traits, small geographic ranges, and small populations [19]. The current scarcity of ecotoxicological data for ground-water organisms is strongly related to the difficulties in sampling, transporting, and rearing them in the lab $[16,19,21]$. Hence, groundwater ERA frequently relies on broad-based extrapolations such as using responses of surface organisms as surrogates and applying large assessment factors to accommodate data uncertainty [16,22]. Still, many studies have demonstrated that the use of surrogate organisms may under or overestimate the assessment of the ecological risk with considerable pernicious ecological and economic effects $[7,8,23,24]$.

In this context, the aim of our work was to develop a novel protocol for acute in situ testing that can be used as a reliable alternative to standard acute lab tests for the assessment of anthropogenic stressors in native groundwater crustaceans. Since groundwater organisms are difficult to sample, have small populations, and the number of organisms available for ecotoxicity testing are extremely limited $[16,19]$, we used the freshwater isopod Asellus aquaticus to develop the protocol. $\mathrm{NaCl}$ was selected as a stressor and lethal responses of asellids to osmotic stress were estimated after 48 and $96 \mathrm{~h}$ of exposure. We tested for the most suitable acute exposure conditions, which included testing the effects of the following variables:

(1) Location-in situ vs. standard lab conditions-since groundwater species are difficult to transport and maintain in the lab [16,19];

(2) Test medium-synthetic vs. filtered field water-considering that organisms are presumably adapted to the physico-chemical conditions of the water in which they live $[15,25]$;

(3) Relevance of substrate-presence vs. absence-because asellids are thigmotactic benthic organisms with a preference for rough surfaces [26];

(4) Replicability: testing was repeated both in the lab and in situ in two consecutive years. 
Then, we applied the protocol to three groundwater-adapted isopods living in caves, Proasellus assaforensis, P. cavaticus and P. lusitanicus, which we also used to test for the effect of location, medium, and substrate, respectively.

\section{Materials and Methods}

\subsection{Development and Test Validation with Asellus Aquaticus}

We selected as a test organism the freshwater species A. aquaticus (Linnaeus, 1758), and collected specimens from a population living in a small creek in the Botanical Garden in Copenhagen, Denmark (55 $\left.41^{\prime} 12.21^{\prime \prime} \mathrm{N}, 12^{\circ} 34^{\prime} 23.83^{\prime \prime} \mathrm{E}\right)$. Specimens were collected during the summer seasons of 2018 and 2019 (Figure 1). Specimens were individually picked from submerged stones or the streambed using brushes and placed randomly in sealable $1 \mathrm{~L}$ plastic containers filled with local freshwater. They were sorted under a portable stereomicroscope Leica EZ4. Specimens of similar size were selected to minimize age differences, and ovigerous females were excluded (i.e., those carrying eggs in the marsupium). Diseased and parasitized specimens were removed according to [27], and organisms were kept under observation for $24 \mathrm{~h}$ to discard the stock's use if $5 \%$ of the collected organisms were dead or showed signs of stress [28]. Specimens tested in situ were kept in a plastic container, which was deposited in the bottom of the stream (natural exposure temperatures available in Table S1). Specimens tested under lab conditions were transported in a portable cooler to the lab and acclimated in an environmental cabinet (Binder KB 240) at the mean summer temperature of the collection site, $17{ }^{\circ} \mathrm{C}$ [29], with a light:dark photoperiod of 16L:8D during $24 \mathrm{~h}$. All organisms tested were deposited in the collection of the Natural History Museum of Denmark.

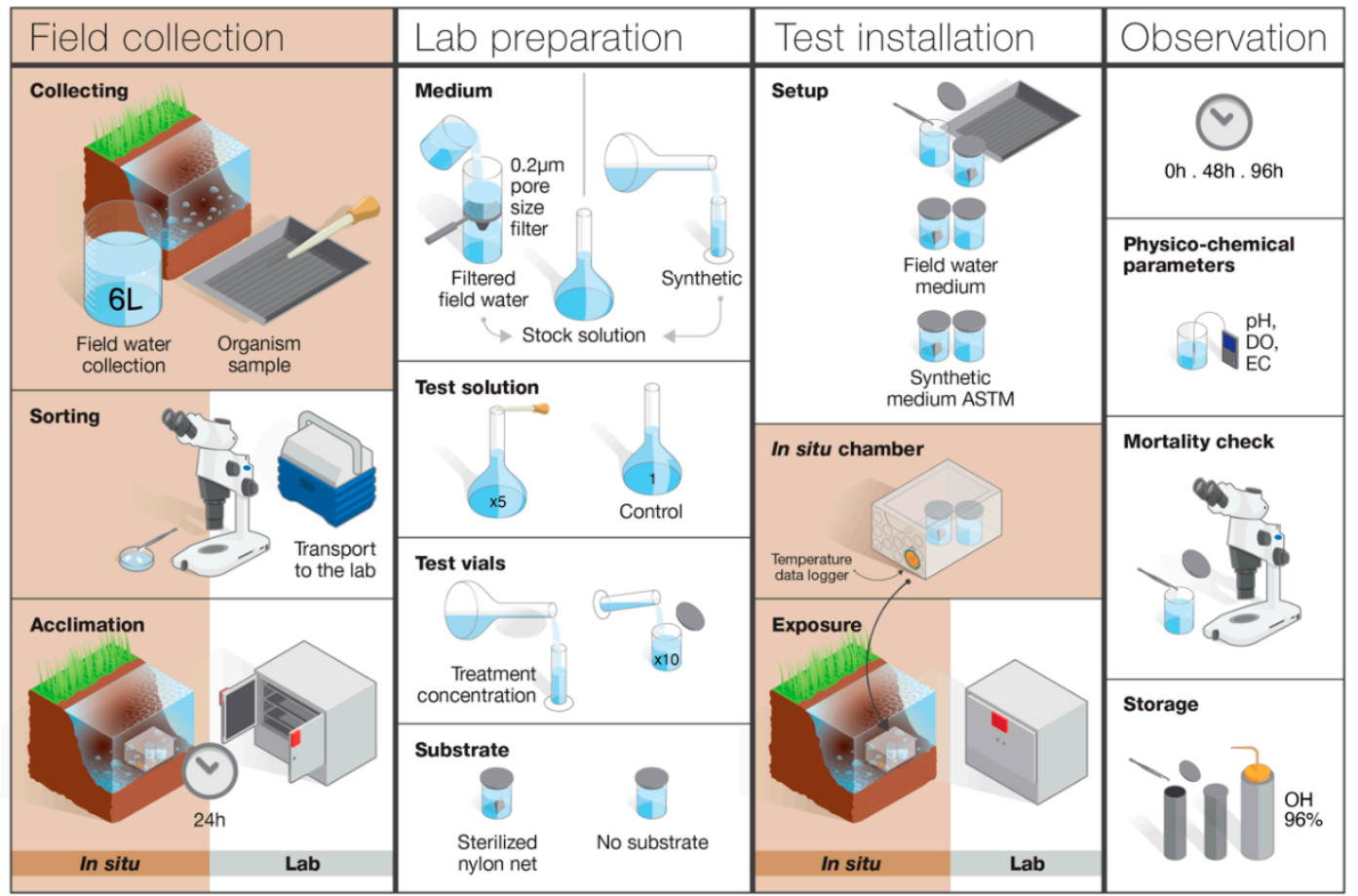

Figure 1. Overview of the experimental design.

Acute toxicity tests were carried out over $96 \mathrm{~h}$ using sodium chloride [CAS]: 7647-14-5 (Sigma-Aldrich, St Quentin-Fallavier, France, 99\% purity) as a stressor. We tested for the effects of location, evaluating the differences between lab and in situ approaches; medium, using either synthetic or filtered field water; and substrate, performing the test either with or without a nylon net inserted into the testing vials. As recommended for ecotoxicity testing with groundwater-adapted isopods and to allow comparison with standard lab tests with crustaceans, we recorded mortality at two exposure times: 48 and $96 \mathrm{~h}[16,28,30]$. 
To evaluate the replicability of the protocol, the acute in situ and lab tests were replicated one year later (summer of 2018 and 2019), using both synthetic water and filtered field water, while the use of substrate was discarded in the second replicate. In both replicates, tests were carried out at the same time in situ and under lab conditions (Figure 1).

The standard ASTM hard water medium (sterile distilled water adding $192 \mathrm{mg} / \mathrm{L}$ $\mathrm{NaHCO}_{3}, 120 \mathrm{mg} / \mathrm{L} \mathrm{CaSO}_{4} \cdot 2 \mathrm{H}_{2} \mathrm{O}, 120 \mathrm{mg} / \mathrm{L} \mathrm{MgSO}_{4}$, and $8 \mathrm{mg} / \mathrm{L} \mathrm{KCl}$ ) was used as a synthetic medium. The field water was filtered immediately after collection, using a $0.45 \mu \mathrm{m}$ pore size, to ensure starvation conditions and remove potential predators. It was used as a control medium and diluent water. The salt concentration in field waters used as controls are provided in Supplementary Table S2. The salt concentrations in the five treatments used during each test were checked using measurements of electrical conductivity (Table S3).

All tests were conducted in hermetic plastic vials $(40 \mathrm{~mL}$ vol and $29 \mathrm{~mm} \varnothing)$ filled with $25 \mathrm{~mL}$ of testing medium, without aeration or food addition and a sterilized nylon net $(2 \times 2 \mathrm{~cm})$ was used as a substrate in the test where it was required. Organisms were tested individually to avoid cannibalism and interaction stress. A total of 10 specimens were tested per treatment concentration and control.

In the tests performed under lab conditions the test vials were placed in an environmental cabinet (KB 240, Binder, Hillerød, Denmark), with the same conditions as the acclimation period. For the test performed in situ during the experiment the vials were introduced in an in situ chamber. The in situ chamber was a transparent container with holes for the site water to flow around the vials. The chamber protected the vials and allowed them to be exposed to the natural environmental conditions (temperature and photoperiod). The temperature at which organisms were exposed was recorded hourly with a temperature datalogger placed in the chamber (TidbiT ${ }^{\circledR}$ v2 Temp UTBI-001, Onset, Bourne, MA, USA) (Figure 1, Table S1).

Test validation followed the OECD (2004) criteria, i.e., mortality rate in control below $10 \%$, pH variation below 1.5 units, and DO variation smaller than $3 \mathrm{mg} / \mathrm{L}$, throughout the test [16,30]. Mortality followed the OECD (2004) criteria, defined as a lack of movement or swimming after gentle stimulation by a sorting needle, and it was recorded at $48 \mathrm{~h}$ and $96 \mathrm{~h}$ in each test vial (Figure 1).

\subsection{Testing Groundwater-Adapted Isopods}

To evaluate the validity of the protocol for groundwater-adapted crustaceans, we selected three cave isopods of the genus Proasellus Dudich, 1925, which have been previously used in lab bioassays [31,32]. We used each of the three Proasellus species to test separately for the effect of medium, substrate, and location. Contrary to the surface water isopod A. aquaticus, groundwater isopods were present in too small numbers in their natural environment to test simultaneously for each species the effect of the three variables [15]. The study design and site for each species are provided in Table 1: P. assaforensis Afonso, 1988, P. cavaticus (Leydig, 1871) and P. lusitanicus (Frade, 1938) were used to test for the effect of location (lab versus in situ test), medium (synthetic vs. filtered field water), and substrate (with or without a nylon net), respectively.

Table 1. Collection sites and test conditions for the groundwater-adapted crustaceans P. assaforensis, P. cavaticus, and P. lusitanicus. T corresponds to the mean temperature during the in situ experiment or to the fixed temperature used in the lab. For each species, the larger "+" signs indicate the two modalities of the effect which was tested for.

\begin{tabular}{|c|c|c|c|c|c|c|c|c|c|c|}
\hline \multirow[b]{2}{*}{ Species } & \multirow[b]{2}{*}{ Site } & \multirow[b]{2}{*}{ Latitude } & \multirow[b]{2}{*}{ Longitude } & \multirow[b]{2}{*}{$\mathrm{T}\left({ }^{\circ} \mathrm{C}\right)$} & \multicolumn{2}{|c|}{ Location } & \multicolumn{2}{|c|}{ Medium } & \multicolumn{2}{|c|}{ Substrate } \\
\hline & & & & & Cave & Lab & Synthetic & $\begin{array}{l}\text { Field } \\
\text { Water }\end{array}$ & Net & $\begin{array}{l}\text { No } \\
\text { Net }\end{array}$ \\
\hline P. assaforensis & Assafora Cave & $38^{\circ} 54^{\prime} 31.15^{\prime \prime} \mathrm{N}$ & $-9^{\circ} 25^{\prime} 18.89^{\prime \prime} \mathrm{E}$ & $\begin{array}{c}16.6 \text { (cave) } \\
16 \text { (lab) }\end{array}$ & + & + & & + & + & \\
\hline $\begin{array}{l}\text { P. cavaticus } \\
\text { P. lusitanicus }\end{array}$ & $\begin{array}{l}\text { Baume la Fraite Cave } \\
\text { Olho de Mira Cave }\end{array}$ & $\begin{array}{c}46^{\circ} 31^{\prime} 30^{\prime \prime} \mathrm{N} \\
39^{\circ} 32^{\prime} 29.01^{\prime \prime} \mathrm{N}\end{array}$ & $\begin{array}{c}5^{\circ} 44^{\prime} 02^{\prime \prime} \mathrm{E} \\
-8^{\circ} 43^{\prime} 19.93^{\prime \prime} \mathrm{E}\end{array}$ & $\begin{array}{l}10.08 \\
13.05\end{array}$ & $\begin{array}{l}+ \\
+\end{array}$ & & + & $\begin{array}{l}+ \\
+\end{array}$ & $\begin{array}{l}+ \\
+\end{array}$ & + \\
\hline
\end{tabular}




\subsection{Field Water Characterization}

The physico-chemical content of field water used as a medium was analyzed for each location (Table S2). Concentrations of TOC, N-NH4 ${ }^{+}, \mathrm{N}_{-} \mathrm{NO}_{2}{ }^{-}, \mathrm{N}-\mathrm{NO}_{3}{ }^{-}$, and $\mathrm{P}_{-} \mathrm{PO}_{4}{ }^{3-}$ were determined spectrophotometrically (Varian Cary 50 UV-Vis, Agilent Technologies, Santa Clara, CA, USA). Chlorides were analyzed by the argentometric method and concentration of total organic carbon (TOC) by TOC analyzer (Multi N/C 3100, Analytik Jena, Jena, Germany). The concentrations of $\mathrm{Na}^{+} \mathrm{K}^{+} \mathrm{Mg}^{2+} \mathrm{Ca}^{2+}$ and metals- $\mathrm{Ag}, \mathrm{Al}, \mathrm{As}, \mathrm{Cd}, \mathrm{Co}$, $\mathrm{Cu}, \mathrm{Fe}, \mathrm{Mn}, \mathrm{Pb}$ and $\mathrm{Zn}$-were analyzed by ICP-MS (Agilent 7900ce, Agilent Technologies, Santa Clara, CA, USA). All methods were performed according to the American Water Works Association standards [33]. Temperature, $\mathrm{pH}$, electrical conductivity, and dissolved oxygen were measured using a multi-parameter probe (Aquaprobe AP-2000, Aquaread, Broadstairs, England).

\subsection{Statistical Analyses}

Dose-response data for the first replicate test with A. aquaticus were fitted using a generalized linear model (glm) and probit link, with time (48 and $96 \mathrm{~h}$ ), location (lab vs. in situ), medium (synthetic vs. filtered field water), and substrate (net vs. no net) as factors, and $\log$ (salinity treatment concentrations) as covariate, and interactions between all of them. A second glm model was performed including time, location, medium, and replicate (first—2018 and second-2019) as factors with their interactions, to analyze replicability. Dose response data for P. assaforensis, P. cavaticus, and P. lusitanicus were fitted with glm models including the controlled variables (either medium, substrate, or location) and time (48 and $96 \mathrm{~h}$ ) as factors and their interactions were considered. All statistical analyses were performed in R 3.5.0 using the "stats", "emmeans", and "ggplot2" packages [34]. Lethal concentrations which affect $50 \%$ of the population $\left(\mathrm{LC}_{50}\right)$ were obtained using the LabApplStat package [35]. Statistical differences (alpha level set at 0.05) in response to salt dose between different variables were tested using a paired one-way ANOVA with the emmeans package [36]. Data were visualized using the ggplot2 package [37].

\section{Results}

We found large variation in $\mathrm{LC}_{50}$ for each species depending on the test conditions. The acute sensitivity to $\mathrm{NaCl}$, expressed as $\mathrm{LC}_{50}$ ranged from $9.4 \mathrm{~g} \mathrm{NaCl} / \mathrm{L}$ at $96 \mathrm{~h}$ to $15.8 \mathrm{~g}$ $\mathrm{NaCl} / \mathrm{L}$ at $48 \mathrm{~h}$ for $A$. aquaticus; from $10.1 \mathrm{~g} \mathrm{NaCl} / \mathrm{L}$ at $96 \mathrm{~h}$ to $13.9 \mathrm{~g} \mathrm{NaCl} / \mathrm{L}$ at $48 \mathrm{~h}$ for P. cavaticus; from $12.7 \mathrm{~g} \mathrm{NaCl} / \mathrm{L}$ at $96 \mathrm{~h}$ to $16.9 \mathrm{~g} \mathrm{NaCl} / \mathrm{L}$ at $48 \mathrm{~h}$ for $P$. lusitanicus; and from $12.3 \mathrm{~g} \mathrm{NaCl} / \mathrm{L}$ at $96 \mathrm{~h}$ to $15.7 \mathrm{~g} \mathrm{NaCl} / \mathrm{L}$ at $48 \mathrm{~h}$ for P. assaforensis (Table S4).

\subsection{Development and Test Validation with Asellus Aquaticus}

For $A$. aquaticus, we found no significant differences in $\mathrm{LC}_{50}$ between in situ and lab experimental setups under the same conditions including comparison across the two replicates (Figures 2 and 3, Tables S5a and S6a). The LC 50 were significantly lower with synthetic medium, except for the two comparisons between the $48 \mathrm{~h}$ filtered field-water lab test of the first replicate and the $48 \mathrm{~h}$ synthetic-water in situ and lab tests of the first replicate ( $p=0.626$ and 0.695, respectively) (Figures 2 and 3, and Tables S5b, S6b and S6c).

The effect of substrate (presence vs. absence of the net) tested in the first replicate experiment with $A$. aquaticus did not provide any significant differences on salinity sensitivity under the same experimental setups (Figure 3, Table S5c). In the study of the replicability, no significant differences in sensitivity were observed between the replicate lab experiments performed in 2018 and 2019, neither between the replicates for the in situ experiments, even though the temperature was slightly different between them (Figure 2, and Tables S1 and S6a). 


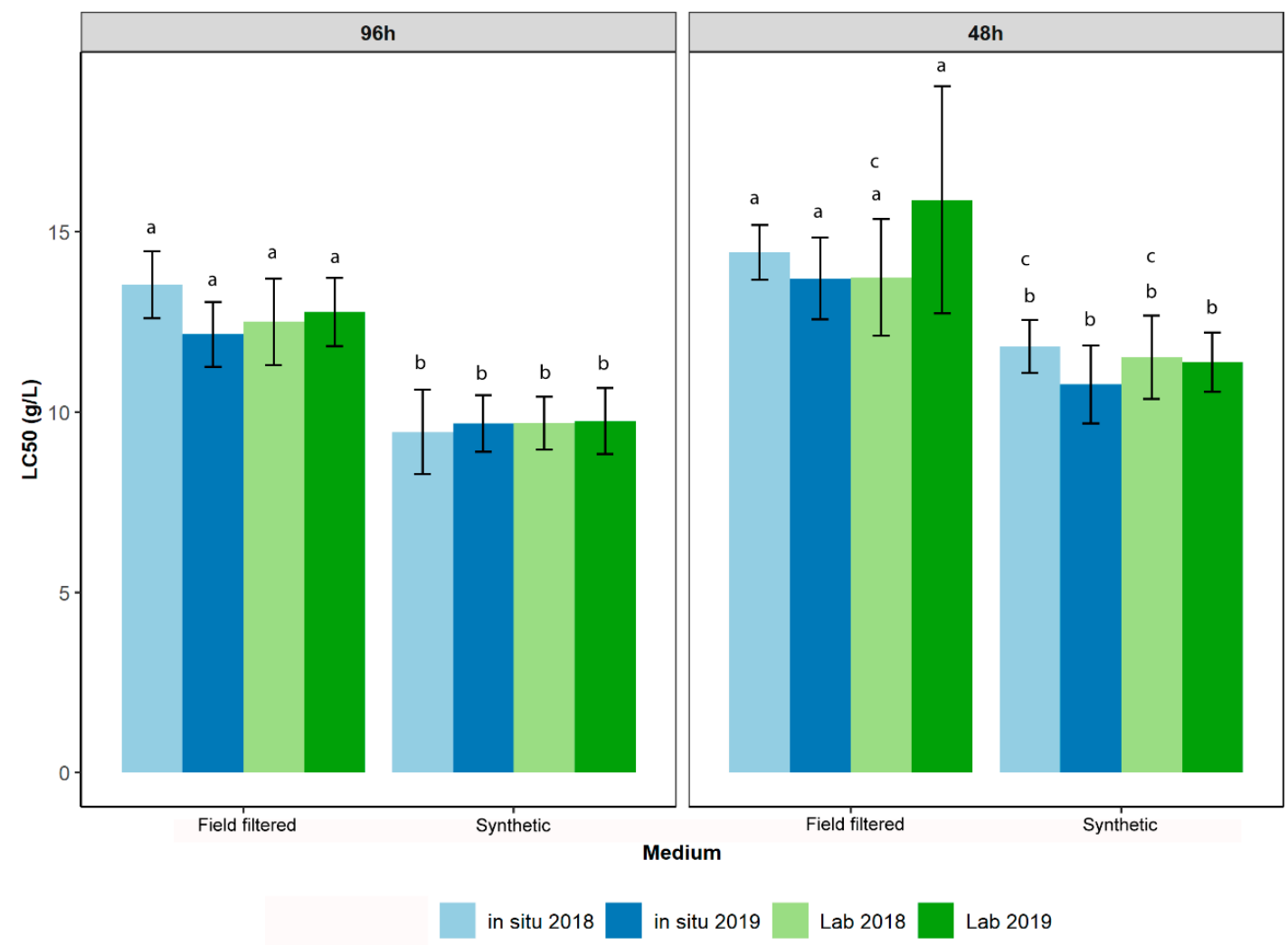

Figure 2. Differences in the lethal $\mathrm{NaCl}$ concentration values affecting $50 \%$ of test populations ( $\mathrm{LC}_{50}$ ) at 48 and $96 \mathrm{~h}$ for A. aquaticus considering the different test medium conditions (field filtered or synthetic medium) and replicate tests performed in 2018 and 2019. Different letters near error bars indicate significant differences between lethal concentrations at $96 \mathrm{~h}$ and $48 \mathrm{~h}(p<0.05)$.

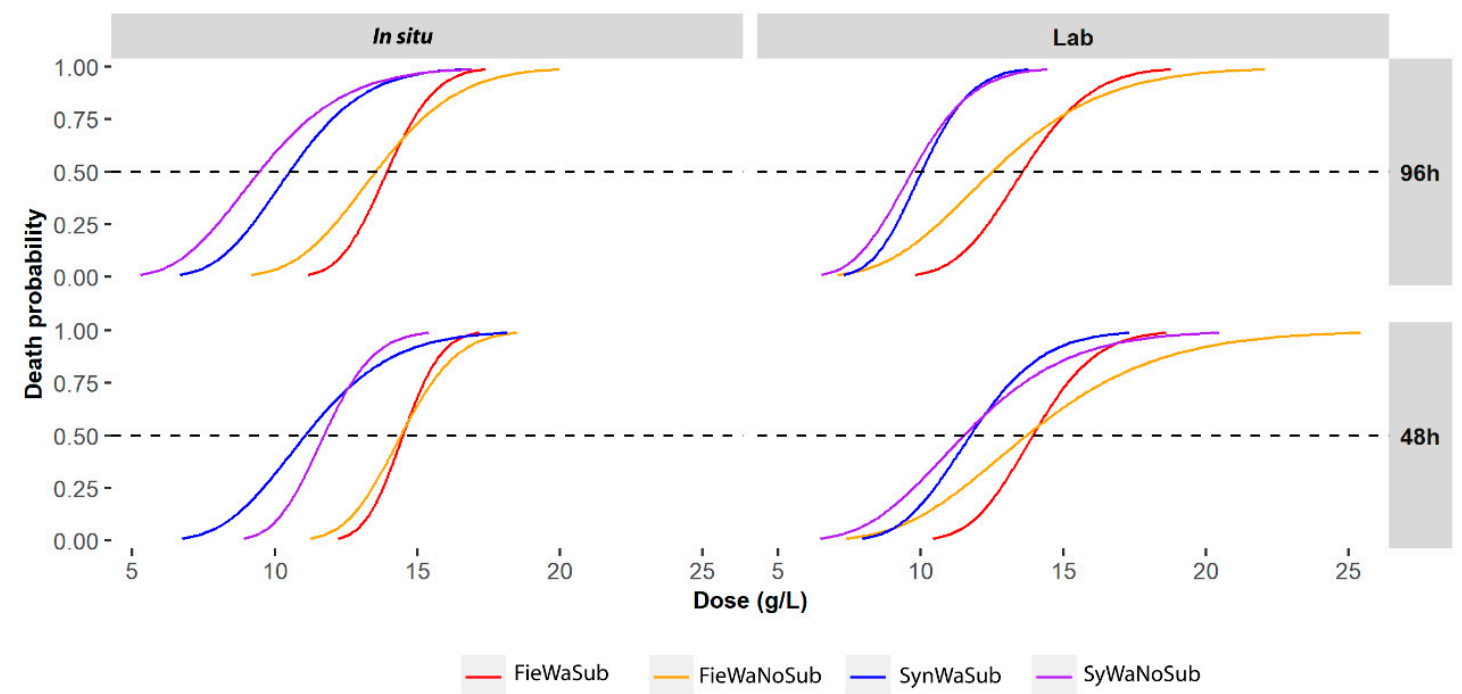

Figure 3. Acute $\mathrm{NaCl}(\mathrm{g} / \mathrm{L})$ dose-response curves for A. aquaticus in situ and under lab conditions at $48 \mathrm{~h}$ and $96 \mathrm{~h}$ for the first replicate experiment. Different test conditions: SynWaSub, synthetic ASTM water with substrate; SynWaNoSub, synthetic ASTM water without substrate; FieWaSub field collected water with substrate; FieWaNoSub, field collected water without substrate. 


\subsection{Testing Groundwater-Adapted Isopods}

Contrarily to the results observed for A. aquaticus, P. assaforensis showed a higher sensitivity to $\mathrm{NaCl}$ under lab conditions than in situ at $48 \mathrm{~h}$ (Figure 4B). For the two other factors tested using groundwater-adapted species, the results were consistent with those observed for A. aquaticus. P. cavaticus was more sensitive to increasing concentrations of salt when using synthetic water as a medium (Figure 4C). Moreover, we found no statistical differences in the sensitivity of P. lusitanicus between the tests with and without substrate (Figure 4D).

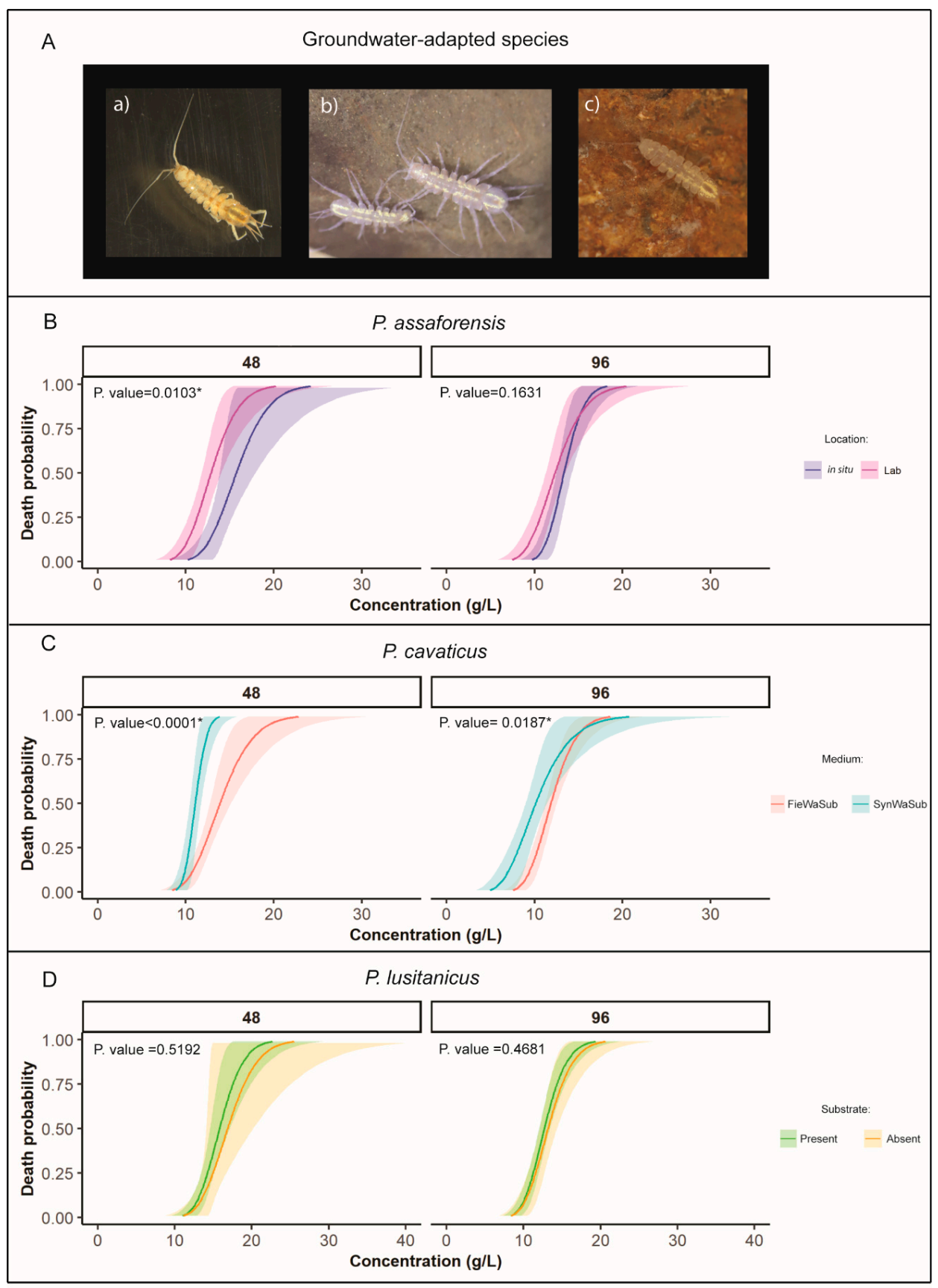

Figure 4. $\mathrm{NaCl}$ dose-response curves for groundwater-adapted species at 48 and $96 \mathrm{~h}$. (A) Habitus: (a) Proasellus assaforensis; (b) P. cavaticus; and (c) P. lusitanicus; (B) Comparison between in situ and lab conditions using P. assaforensis; (C) Medium comparison using P. cavaticus in situ; (D) Substrate use comparison using P. lusitanicus. See Table 1 for the experimental design used for each groundwater species. FieWaSub corresponds to field collected water and SynWaSub to synthetic ASTM medium. * Significant value. 


\section{Discussion}

Acute in situ testing approaches have the wide advantage of using realistic environmental conditions. Additionally, it also allows the use of local specimens avoiding transportation and lab acclimation. This is particularly critical for groundwater-adapted fauna, which often have a very narrow thermal niche breadth $[10,38,39]$.

Asellus aquaticus was selected as a model organism to develop and validate the protocol because it has recently been suggested as a model for biomonitoring environmental pollution [40]. A. aquaticus has been successfully used in lab and in situ ecotoxicological studies using field collected organisms [41-43], and stable lab cultures have been successfully raised [27,44]. A. aquaticus responded similarly to increasing $\mathrm{NaCl}$ concentrations in situ and under lab conditions using the same medium conditions. This indicates that transportation and acclimation to the lab did not affect the organisms' fitness, dismissing a possible overestimation of sensitivity for the tests performed under lab conditions.

Contrary to the results observed with A. aquaticus, the groundwater-adapted species $P$. assaforensis showed higher mortalities at $48 \mathrm{~h}$ in lab conditions than in cave conditions. Because thermal and light conditions were the same between the cave and the lab, we suggest that either the transportation or the acclimation process affected the fitness of P. assaforensis. This finding corroborates the difficulties encountered in a number of studies when running ecotoxicological testing under lab conditions with groundwater-adapted fauna $[15,16,19]$. It also suggests that in situ tests developed in this study are likely to generate more reliable acute data than lab tests for native crustaceans that are highly sensitive to transportation and rearing conditions.

The use of synthetic medium consistently resulted in higher sensitivity to $\mathrm{NaCl}$ than field water in both surface and groundwater isopods. Synthetic mediums are aimed to isolate the stressor effect from the interaction with the water matrix, therefore they are composed only of few salts $[41,45,46]$. However, the use of field collected water as a medium is already integrated in some standardized acute ecotoxicity tests, e.g., "clean surface water, groundwater or reconstituted water are acceptable as dilution water" [28]. Nevertheless, $[25,47]$ suggested that the lack of trace and essential elements such as $\mathrm{Cu}$ in synthetic mediums may limit the organisms' survival. Moreover, synthetic medium has different physico-chemical properties than the natural medium in which the organisms are collected. Hence, the physico-chemistry of synthetic water may influence the organisms' physiology and interfere with the effect of the toxicants [48]. The synthetic water used in the present protocol was consistently less concentrated in salts than the site water of the four tested species. Hence, the acclimation to the synthetic water may have induced a first osmotic stress to which we added a second inverse osmotic stress when submitting the organisms to increasing concentrations of $\mathrm{NaCl}$.

We found no differences in mortality between tests performed with and without substrate both for A. aquaticus and P. lusitanicus. The use of a substrate is recommended when testing epibenthic organisms [26] because they can hardly attach to the vials surface. In natural conditions, many epibenthic organisms also tend to hide below diverse substrates (e.g., stones, leaves). Hence, the lack of a substrate may increase energetic expenditures due to increased locomotory activity or increased levels of stress, thereby increasing mortality. In the present study, we observed that intense pleopod movements at high $\mathrm{NaCl}$ concentrations raised the organisms in the water column and that they could no longer stabilize themselves. However, substrate may also bias mortality if the substance to be tested can adsorb onto it. As long as the potential for adsorption is low, as is the case with $\mathrm{NaCl}$, we recommend using substrates when testing epibenthic organisms.

By repeating the test after a year with $A$. aquaticus we were able to confirm the response patterns observed in the first replicate study. Although the mean environmental temperatures recorded during the two in situ tests of $A$. aquaticus were slightly lower $\left(-1.3^{\circ} \mathrm{C}\right.$, in 2018) or higher $\left(+4^{\circ} \mathrm{C}\right.$, in 2019) than the medium summer temperature used as a fixed temperature in lab test, we found no significant difference in the response to $\mathrm{NaCl}$ between replicates at the lab and in situ testing. This suggests that the difference in 
temperature between in situ and lab tests was small enough to avoid causing a thermal shock that would have influenced the response of A. aquaticus to salt (see [39]).

Acute lab tests are performed at stable temperatures within the range of the organism's optimal conditions. Yet, temperature stability in ecotoxicity testing lacks environmental realism $[48,49]$. Temperature affects the physiological processes of ectotherm organisms such as metabolic rate and locomotory and feeding activities, which influence the stressors' effects on organisms in terms of uptake, elimination, and detoxication rates of chemicals [50-52]. Therefore, acute in situ testing can be used to study the response of stressors considering a realistic thermal exposure. However, the uncertainty of the temperature variability of in situ test disappears when working with groundwater organisms. The stable annual temperatures usually observed in groundwater habitats [10] and the lack of fast temperature fluctuation facilitate the comparison between in situ and lab tests.

Acute lab testing typically evaluates the lethal effect of a chemical under barren conditions, using controlled environmental variables. This allows comparing the obtained results with those available in databases [49]. A major caveat of acute lab testing is the lack of environmental realism [13], which is provided by in situ methodologies. However, standardization is more difficult because of the environmental heterogeneity, especially regarding the physico-chemical water conditions (and temperature in surface environments). In situ testing approaches have been performed by exposing model or non-native organisms to site-specific conditions (e.g., in situ caging experiments [14]). Compared to lab and in situ testing using caged organisms exposed to a continuum water flux (i.e., open water circulation), our novel in situ protocol has the advantage of using site-specific organisms and field water as medium (i.e., with known physico-chemical characteristics). The novel acute in situ testing provides an efficient method for evaluating site-specific scenarios for potential biodiversity changes in response to variation in the concentration of selected stressors. In the present study, $\mathrm{NaCl}$ was selected for developing the in situ test, but the use of the test can be expanded and applied to other stressors. Moreover, the use of native organisms under in situ conditions reduces transportation, acclimation and the risk of introducing species into the ecosystems.

There are three prerequisites for deploying acute in situ testing:

(i) Site and stressors' selection: broad knowledge of the selected site including the environmental characterization of the anthropogenic hazard. It implies the characterization of sources and pathways of contaminants which affect the ecosystem and the identification of potential new pollutants [53-57];

(ii) Water matrix characterization: description of the physico-chemical characteristics of water used as a medium and ensuring the stability of the stressor under study $[28,30]$. Indeed, the behavior of the stressor can be affected by interactions with several characteristics of the water matrix, including $\mathrm{pH}$ and temperature, thereby modifying the concentrations to which the organisms are exposed. Chemical analyses also provide baseline data of the chemicals to which organisms are exposed;

(iii) Selection of the test organisms: an ecosystem characterization is recommended for selecting organisms that are representative of the study ecosystem and have an important role in the food web $[23,58]$. In the present study, we focused on crustaceans because of their abundance and ecological relevance in groundwater ecosystems [59]. Specifically, isopods are primary consumers, an important food source for other trophic levels, and are included in regulatory assessment schemes for chemicals [41]. However, the novel acute in situ protocol can be adapted for other organisms, including other crustacean groups.

\section{Conclusions}

The proposed protocol for acute in situ testing has the potential to increase the availability of ecotoxicological data for ERA of groundwater ecosystems. This is fundamental because the use of surface organisms as surrogates for groundwater ecosystem risk assessment is increasingly debated. The proposed protocol is actually being used to test 
for differences in the sensitivity of multiple surface and groundwater species of asellid crustaceans to different stressors. When analyzed within the context of a comparative phylogenetic approach, such sensitivity data may prove to be essential to test for different sensitivity among surface and groundwater organisms, thereby bringing robust arguments into the debate on the use of surrogate organisms in ERA.

Our protocol represents a major step towards generating acute ecotoxicity data for groundwater species (and other native crustaceans in a wide range of ecosystems) that can be used for ERA. However, future research on groundwater ecotoxicity should also focus on developing new methods for assessing chronic impacts and sublethal endpoints [19].

Supplementary Materials: The following are available online at https: / www.mdpi.com/article / 10.3390/w13081132/s1, Table S1: Temperatures measured in the in situ climatic chamber during the experiments. (a) A. aquaticus first tests replicate, (b) A. aquaticus second tests replicate, (c) P. assaforensis, (d) P. cavaticus, and (e) P. lusitanicus; Table S2: Chemical analysis and parameters of synthetic and field water of each locality used as medium. EC, electrical conductivity; DO, dissolved oxygen; TOC, total organic carbon; n.d., not detected; Table S3: NaCl nominal concentration ( $\mathrm{g} \mathrm{NaCl} / \mathrm{L}$ ) and electrical conductivity $(\mathrm{EC} \mathrm{mS} / \mathrm{cm}$ ) for the different experiments; Table S4: Variability in the lethal $\mathrm{NaCl}$ concentration values affecting $50 \%$ of test populations $\left(\mathrm{LC}_{50}\right)$ at $48-96 \mathrm{~h}$ exposure for the tested species. Location: in situ or laboratory (lab) conditions. Medium: synthetic water (SynWa) or field water (FilWa); Substrate: with a substrate (net) or without (absence); Table S5: pairwise comparisons for the first replicate test with A. aquaticus. Variables analyzed: (a) the effect of location within time and medium; (b) the effect of medium within time; and (c) the effect of the substrate within time, medium and location. Pink pattern: Statistically significant results; Table S6: pairwise comparisons considering the two replicates test with A. aquaticus. Variables analyzed: (a) the effect of location considering replicates independently within medium and time; (b) effect of medium within time; and (c) the effect of all variables across each other. Pink pattern: Statistically significant results.

Author Contributions: Conceptualization, A.S.P.S.R. and F.M.; methodology, A.C.-S., F.M., G.K. and A.S.P.S.R.; validation, A.C.-S., F.M., G.K. and A.S.P.S.R.; formal analysis, A.C.-S. and G.K.; investigation, A.C.-S., F.M. and A.S.P.S.R.; resources, A.S.P.S.R., F.M. and G.K.; data curation, A.C.-S., F.M., G.K. and A.S.P.S.R.; writing-original draft preparation, A.C.-S. and A.S.P.S.R.; writing一review and editing, F.M., G.K. and A.S.P.S.R.; visualization, A.C.-S. and A.S.P.S.R.; supervision, A.S.P.S.R.; project administration, A.S.P.S.R.; funding acquisition, A.S.P.S.R., F.M. and G.K. All authors have read and agreed to the published version of the manuscript.

Funding: This work was supported by a research grant (15471) from the VILLUM FONDEN, by the French National Research Agency and EUR H2O'Lyon (ANR-17-EURE-0018), by the Slovenian Research Agency (Research program Chemical engineering (P2-0191)), and by Portuguese National Funds through "Fundação para a Ciência e Tecnologia" (FCT) within the cE3c Unit funding UIDB/00329/2020.

Institutional Review Board Statement: Not applicable.

Informed Consent Statement: Not applicable.

Data Availability Statement: The data presented in this study is available in the current manuscript and the Supplementary Materials are available online at: https://www.mdpi.com/article/10.3390/ w13081132/s1 (accessed on 19 April 2021).

Acknowledgments: We express our gratitude to Olímpio Martins, Maria João Martins, and Alcides Ribeiro for the support in fieldwork, to Bo Markussen of the Data Science Lab of the University of Copenhagen for assistance with the statistical analysis, and to Gregor Marolt for analysis of metals.

Conflicts of Interest: The authors declare no conflict of interest.

\section{References}

1. Hope, B.K. An examination of ecological risk assessment and management practices. Environ. Int. 2006, 32, 983-995. [CrossRef]

2. Rohr, J.R.; Salice, C.J.; Nisbet, R.M. The pros and cons of ecological risk assessment based on data from different levels of biological organization. Crit. Rev. Toxicol. 2016, 46, 756-784. [CrossRef]

3. Boyle, T.P.; Fairchild, J.F. The Role of Mesocosm Studies in Ecological Risk Analysis. Ecol. Appl. 1997, 7, 1099-1102. [CrossRef] 
4. Maltby, L.; Blake, N.; Brock, T.C.M.; Van den Brink, P.J. Insecticide species sensitivity distributions: Importance of test species selection and relevance to aquatic ecosystems. Environ. Toxicol. Chem. 2005, 24, 379-388. [CrossRef]

5. ECOTOX-Database. Available online: https://cfpub.epa.gov/ecotox (accessed on 10 December 2020).

6. EC. Technical Guidance Document in Support of Commission Directive 93/67/EEC on Risk Assessment for New Notified Substances and Commission Regulation (EC) No 1488/94 on Risk Assessment for Exiting Substances; European Commission: Luxembourg, 2003.

7. Hose, G.C. Assessing the Need for Groundwater Quality Guidelines for Pesticides Using the Species Sensitivity Distribution Approach. Hum. Ecol. Risk Assess. 2005, 11, 951-966. [CrossRef]

8. Leung, K.M.; Morritt, D.; Wheeler, J.R.; Whitehouse, P.; Sorokin, N.; Toy, R.; Holt, M.; Crane, M. Can Saltwater Toxicity be Predicted from Freshwater Data? Mar. Pollut. Bull. 2001, 42, 1007-1013. [CrossRef]

9. Adam, N.; Schmitt, C.; De Bruyn, L.; Knapen, D.; Blust, R. Aquatic acute species sensitivity distributions of ZnO and CuO nanoparticles. Sci. Total Environ. 2015, 526, 233-242. [CrossRef]

10. Castaño-Sánchez, A.; Hose, G.C.; Reboleira, A.S.P.S. Salinity and temperature increase impacts groundwater crustaceans. Sci. Rep. 2020, 10, 12328. [CrossRef]

11. Kulkarni, D.; Gergs, A.; Hommen, U.; Ratte, H.T.; Preuss, T.G. A plea for the use of copepods in freshwater ecotoxicology. Environ. Sci. Pollut. Res. 2013, 20, 75-85. [CrossRef] [PubMed]

12. Crane, M.; Burton, G.A.; Culp, J.M.; Greenberg, M.S.; Munkittrick, K.R.; Ribeiro, R.; Salazar, M.H.; St-Jean, S.D. Review of aquatic in situ approaches for stressor and effect diagnosis. Integr. Environ. Asses. 2007, 3, 234-245. [CrossRef] [PubMed]

13. Baird, D.J.; Brown, S.S.; Lagadic, L.; Liess, M.; Maltby, L.; Moreira-Santos, M.; Schulz, R.; Scott, G.I. In situ-based effects measures: Determining the ecological relevance of measured responses. Integr. Environ. Asses. 2007, 3, 259-267. [CrossRef] [PubMed]

14. Burton, G.A.; Greenberg, M.S.; Rowland, C.D.; Irvine, C.A.; Lavoie, D.R.; Brooker, J.A.; Moore, L.; Raymer, D.F.; McWilliam, R.A. In situ exposures using caged organisms: A multi-compartment approach to detect aquatic toxicity and bioaccumulation. Environ. Pollut. 2005, 134, 133-144. [CrossRef]

15. Gerhardt, A.; Badouin, N.; Weiler, M. In situ online biomonitoring of groundwater quality using freshwater amphipods exposed to organic fertilizer and rainfall events. Curr. Top. Toxicol. 2020, 16, 13-23.

16. Di Lorenzo, T.; Di Marzio, W.D.; Fiasca, B.; Galassi, D.M.P.; Korbel, K.; Iepure, S.; Pereira, J.L.; Reboleira, A.S.P.; Schmidt, S.I.; Hose, G.C. Recommendations for ecotoxicity testing with stygobiotic species in the framework of groundwater environmental risk assessment. Sci. Total Environ. 2019, 681, 292-304. [CrossRef]

17. Lelchat, F.; Dussauze, M.; Lemaire, P.; Theron, M.; Toffin, L.; Le Floch, S. Measuring the biological impact of drilling waste on the deep seafloor: An experimental challenge. J. Hazard. Mater. 2020, 389, 122132. [CrossRef] [PubMed]

18. Breitholtz, M.; Rudén, C.; Ove Hansson, S.; Bengtsson, B.E. Ten challenges for improved ecotoxicological testing in environmental risk assessment. Ecotoxicol. Environ. Saf. 2006, 63, 324-335. [CrossRef]

19. Castaño-Sánchez, A.; Hose, G.C.; Reboleira, A.S.P.S. Ecotoxicological effects of anthropogenic stressors in subterranean organisms: A review. Chemosphere 2020, 244, 125422. [CrossRef]

20. Mammola, S.; Cardoso, P.; Culver, D.C.; Deharveng, L.; Ferreira, R.L.; Fišer, C.; Galassi, D.M.P.; Griebler, C.; Halse, S.; Humphreys, W.F.; et al. Scientists' Warning on the Conservation of Subterranean Ecosystems. BioScience 2019, 69, 641-650. [CrossRef]

21. Di Lorenzo, T.; Di Marzio, W.D.; Sáenz, M.E.; Baratti, M.; DeDonno, A.A.; Iannucci, A.; Cannicci, S.; Messana, G.; Galassi, D.M. Sensitivity of hypogean and epigean freshwater copepods to agricultural pollutants. Environ. Sci. Pollut. Res. 2014, 21, $4643-4655$. [CrossRef]

22. EMA (European Medicines Agency). Guideline on Assessing the Environmental and Human Health Risks of Veterinary Medicinal Products in Groundwater. Committee for Medical Products for Veterinary Use. Available online: https://www.ema.europa.eu/en/documents/scientific-guideline/guideline-assessing-environmental-human-health-risksveterinary-medicinal-products-groundwater_en.pdf (accessed on 15 December 2020).

23. Chapman, P.M. Integrating toxicology and ecology: Putting the "eco" into ecotoxicology. Mar. Pollut. Bull. 2002, 44, 7-15. [CrossRef]

24. Chapman, P.M.; Fairbrother, A.; Brown, D. A critical evaluation of safety (uncertainty) factors for ecological risk assessment. Environ. Toxicol. Chem. 1998, 17, 99-108. [CrossRef]

25. Bossuyt, B.T.A.; Janssen, C.R. Copper toxicity to different field-collected cladoceran species: Intra- and inter-species sensitivity. Environ. Pollut. 2005, 136, 145-154. [CrossRef] [PubMed]

26. Avramov, M.; Schmidt, S.I.; Griebler, C. A new bioassay for the ecotoxicological testing of VOCs on groundwater invertebrates and the effects of toluene on Niphargus inopinatus. Aquat. Toxicol. 2013, 130-131, 1-8. [CrossRef]

27. Bloor, M.C. Animal standardisation for mixed species ecotoxicological studies: Establishing a laboratory breeding programme for Gammarus pulex and Asellus aquaticus. Zool. Baetica 2010, 21, 179-190.

28. US EPA. Ecological Effects Test Guidelines OCSPP 850.1020: Gammarid Amphipod Acute Toxicity Test; Office of Chemical Safety and Pollution Prevention: Washington, DC, USA, 2016.

29. Danish Meteorological Institute. Available online: http://www.dmi.dk (accessed on 15 January 2021).

30. OECD. Test No. 202: Daphnia sp., acute immobilization test, adopted: April 2004. In OECD Guidelines for the Testing of Chemicals; OECD Publishing: Paris, France, 2004.

31. Reboleira, A.S.P.S.; Abrantes, N.; Oromí, P.; Gonçalves, F. Acute toxicity of copper sulfate and potassium dichromate on stygobiont Proasellus: General aspects of groundwater ecotoxicology and future perspectives. Water Air Soil Pollut. 2013, 224, 1550. [CrossRef] 
32. Mermillod-Blondin, F.; Lefour, C.; Lalouette, L.; Renault, D.; Malard, F.; Simon, L.; Douady, C.J. Thermal tolerance breadths among groundwater crustaceans living in a thermally constant environment. J. Exp. Biol. 2013, jeb.081232. [CrossRef] [PubMed]

33. Rice, E.W.; Baird, R.B.; Eaton, A.D. Standard Methods for the Examination of Water and Wastewater, 23rd ed.; American Public Health Association, American Water Works Association and Water Environment Federation: Washington, DC, USA, 2017.

34. R Team. R Development Core Team. R. A. Lang. Environ. Stat. Comput. 2013, 55, 275-286.

35. Markussen, B. LabApplStat: Miscellaneous Scripts Developed at the Data Science Laboratory, University of Copenhagen. 2020. R Package Version 140. Available online: https:/ / github.com/bomarkussen/LabApplStat (accessed on 14 December 2020).

36. Russell, L. Emmeans: Estimated Marginal Means, Aka Least-Squares Means, R Package Version 148; Available online: https: / / cran.r-project.org/web/packages/emmeans/index.html (accessed on 11 December 2020).

37. Wickham, H.; Chang, W.; Henry, L.; Pedersen, T.L.; Takahashi, K.; Wilke, C.; Yutani, H.; Dunnington, D. ggplot2: Create Elegant Data Visualisations Using the Grammar of Graphics, R package Version 332; Available online: https: / / cloud.r-project.org/package=ggplot2 (accessed on 11 December 2020).

38. Mammola, S.; Piano, E.; Cardoso, P.; Vernon, P.; Domínguez-Villar, D.; Culver, D.C.; Pipan, T.; Isaia, M. Climate change going deep: The effects of global climatic alterations on cave ecosystems. Anthr. Rev. 2019, 6, 98-116. [CrossRef]

39. Mammola, S.; Piano, E.; Malard, F.; Vernon, P.; Isaia, M. Extending Janzen's hypothesis to temperate regions: A test using subterranean ecosystems. Funct. Ecol. 2019, 33, 1638-1650. [CrossRef]

40. O'Callaghan, I.; Harrison, S.; Fitzpatrick, D.; Sullivan, T. The freshwater isopod Asellus aquaticus as a model biomonitor of environmental pollution: A review. Chemosphere 2019, 235, 498-509. [CrossRef] [PubMed]

41. Ginneken, M.V.; Blust, R.; Bervoets, L. How lethal concentration changes over time: Toxicity of cadmium, copper, and lead to the freshwater isopod Asellus aquaticus. Environ. Toxicol. Chem. 2017, 36, 2849-2854. [CrossRef]

42. Lagerspetz, K.Y.H. Thermal acclimation without heat shock, and motor responses to a sudden temperature change in Asellus aquaticus. J. Therm. Biol. 2003, 28, 421-427. [CrossRef]

43. Ieromina, O.; Peijnenburg, W.J.G.M.; de Snoo, G.R.; Vijver, M.G. Population responses of Daphnia magna, Chydorus sphaericus and Asellus aquaticus in pesticide contaminated ditches around bulb fields. Environ. Pollut. 2014, 192, 196-203. [CrossRef] [PubMed]

44. De Lange, H.J.; De Haas, E.M.; Maas, H.; Peeters, E.T.H.M. Contaminated sediments and bioassay responses of three macroinvertebrates, the midge larva Chironomus riparius, the water louse Asellus aquaticus and the mayfly nymph Ephoron virgo. Chemosphere 2005, 61, 1700-1709. [CrossRef] [PubMed]

45. Di Marzio, W.D.; Cifoni, M.; Sáenz, M.E.; Galassi, D.M.P.; Di Lorenzo, T. The ecotoxicity of binary mixtures of Imazamox and ionized ammonia on freshwater copepods: Implications for environmental risk assessment in groundwater bodies. Ecotoxicol. Environ. Saf. 2018, 149, 72-79. [CrossRef] [PubMed]

46. Soucek, D.J.; Linton, T.K.; Tarr, C.D.; Dickinson, A.; Wickramanayake, N.; Delos, C.G.; Cruz, L.A. Influence of water hardness and sulfate on the acute toxicity of chloride to sensitive freshwater invertebrates. Environ. Toxicol. Chem. 2011, 30, 930-938. [CrossRef] [PubMed]

47. Canli, M. Effects of copper pre-exposure routes on the energy reserves and subsequent copper toxicity in Daphnia magna. Environ. Toxicol. 2006, 21, 521-527. [CrossRef]

48. Holmstrup, M.; Bindesbøl, A.-M.; Oostingh, G.J.; Duschl, A.; Scheil, V.; Köhler, H.-R.; Loureiro, S.; Soares, A.M.; Ferreira, A.L.; Kienle, C.; et al. Interactions between effects of environmental chemicals and natural stressors: A review. Sci. Total Environ. 2010, 408, 3746-3762. [CrossRef]

49. Laskowski, R.; Bednarska, A.J.; Kramarz, P.E.; Loureiro, S.; Scheil, V.; Kudłek, J.; Holmstrup, M. Interactions between toxic chemicals and natural environmental factors-A meta-analysis and case studies. Sci. Total Environ. 2010, 408, 3763-3774. [CrossRef] [PubMed]

50. Abram, P.K.; Boivin, G.; Moiroux, J.; Brodeur, J. Behavioural effects of temperature on ectothermic animals: Unifying thermal physiology and behavioural plasticity. Biol. Rev. 2017, 92, 1859-1876. [CrossRef] [PubMed]

51. Sokolova, I.M.; Lannig, G. Interactive effects of metal pollution and temperature on metabolism in aquatic ectotherms: Implications of global climate change. Clim. Res. 2008, 37, 181-201. [CrossRef]

52. Schulte, P.M. The effects of temperature on aerobic metabolism: Towards a mechanistic understanding of the responses of ectotherms to a changing environment. J. Exp. Biol. 2015, 218, 1856-1866. [CrossRef] [PubMed]

53. Brack, W.; Dulio, V.; Ågerstrand, M.; Allan, I.; Altenburger, R.; Brinkmann, M.; Bunke, D.; Burgess, R.M.; Cousins, I.; Escher, B.I.; et al. Towards the review of the European Union Water Framework Directive: Recommendations for more efficient assessment and management of chemical contamination in European surface water resources. Sci. Total Environ. 2017, 576, 720-737. [CrossRef]

54. Coquery, M.; Morin, A.; Bécue, A.; Lepot, B. Priority substances of the European Water Framework Directive: Analytical challenges in monitoring water quality. TrAC Trends Anal. Chem. 2005, 24, 117-127. [CrossRef]

55. Stuart, M.; Lapworth, D.; Crane, E.; Hart, A. Review of risk from potential emerging contaminants in UK groundwater. Sci. Total Environ. 2012, 416, 1-21. [CrossRef]

56. Hutchinson, T.H.; Lyons, B.P.; Thain, J.E.; Law, R.J. Evaluating legacy contaminants and emerging chemicals in marine environments using adverse outcome pathways and biological effects-directed analysis. Mar. Pollut. Bull. 2013, 74, 517-525. [CrossRef] [PubMed]

57. Lapworth, D.J.; Baran, N.; Stuart, M.E.; Ward, R.S. Emerging organic contaminants in groundwater: A review of sources, fate and occurrence. Environ. Pollut. 2012, 163, 287-303. [CrossRef] [PubMed] 
58. Martinez-Haro, M.; Beiras, R.; Bellas, J.; Capela, R.; Coelho, J.P.; Lopes, I.; Moreira-Santos, M.; Reis-Henriques, A.M.; Ribeiro, R.; Santos, M.M.; et al. A review on the ecological quality status assessment in aquatic systems using community based indicators and ecotoxicological tools: What might be the added value of their combination? Ecol. Indic. 2015, 48, 8-16. [CrossRef]

59. Zagmajster, M.; Eme, D.; Fišer, C.; Galassi, D.M.; Marmonier, P.; Stoch, F.; Cornu, J.-F.; Malard, F. Geographic variation in range size and beta diversity of groundwater crustaceans: Insights from habitats with low thermal seasonality. Glob. Ecol. Biogeogr. 2014, 23, 1135-1145. [CrossRef] 